\title{
Impact of Obesity on a Chinese Population with Erosive Esophagitis and Barrett's Esophagus
}

\author{
Shou-Wu Lee ${ }^{1,2}$, Han-Chung Lien ${ }^{1,3}$, Teng-Yu Lee ${ }^{1,2}$, Chun-Fang Tung ${ }^{1}$, Hong-Zen Yeh ${ }^{1,3}$, and Chi-Sen Chang ${ }^{1,2}$ \\ ${ }^{1}$ Division of Gastroenterology, Department of Internal Medicine, Taichung Veterans General Hospital, ${ }^{2}$ Department of Internal Medicine, Chung \\ Shan Medical University, Taichung, and ${ }^{3}$ Department of Internal Medicine, National Yang-Ming University School of Medicine, Taipei, Taiwan
}

Background/Aims: The aim of this study was to investigate the associations between obesity and erosive esophagitis (EE) or Barrett's esophagus (BE) in a Chinese population. Methods: Data from subjects were retrospectively collected from 2006 to 2009. Individuals with BE were identified and age- and sex-matched at a 1:2 ratio with normal esophagocardial junction and EE patients. The subjects were stratified into two groups: the normal weight group and overweight/ obesity group (body mass index $\geq 25 \mathrm{mg} / \mathrm{m}^{2}$ ) or the normal waist group and abdominal obesity group (waist circumference $\geq 90 \mathrm{~cm}$ for men and $\geq 80 \mathrm{~cm}$ for women). Results: Overall, 45\%, 72\%, and 52\% were overweight/obese and $23 \%, 65 \%$, and $18 \%$ had abdominal obesity in the normal, $\mathrm{EE}$, and $\mathrm{BE}$ groups, respectively. Positive associations were identified between EE and overweight/obesity (odds ratio [OR], 3.14; 95\% confidence interval [CI], 1.75 to 5.66) and abdominal obesity (OR, 6.22; 95\% Cl, 3.34 to 11.57); however, the associations were nonsignificant between $\mathrm{BE}$ and overweight/obesity (OR, 1.32; $95 \% \mathrm{Cl}, 0.67$ to 2.61) or abdominal obesity (OR, 0.73; 95\% Cl, 0.31 to 1.73). Female BE patients had a significantly increased rate of being overweight/obese. Conclusions: Obesity is a contributing factor in EE. The association of BE and obesity was not significant, with the exception of female BE cases. (Gut Liver 2017;11:377-382)

Key Words: Barrett esophagus; Gastroesophageal reflux; Obesity

\section{INTRODUCTION}

Patients with gastroesophageal reflux disease (GERD) may present with a broad range of troublesome symptoms that can impair quality of daily life. ${ }^{1}$ Barrett's esophagus (BE) is a premalignant lesion in adenocarcinoma of the esophagus and gastroesophageal junction. ${ }^{2}$ The incidence of GERD is increasing in the East as well as in the West, and obesity was found to be a significant risk factor in the development of severe forms of GERD. ${ }^{3}$ There is strong evidence from epidemiological studies of populations with high prevalence rates of obesity, as measured by body mass index (BMI), showing associations of overweight with GERD symptoms and erosive esophagitis (EE). ${ }^{3,4}$ In contrast, it remains controversial whether obesity is actually an independent risk factor for BE. Furthermore, there are race and gender differences in the distribution of BE. ${ }^{5}$ The aim of the study was to investigate the associations between obesity and $\mathrm{EE}$, or $\mathrm{BE}$, in a Chinese population in Taiwan.

\section{MATERIALS AND METHODS}

Data from subjects who visited the Medical Screening Center at Taichung Veterans General Hospital were retrospectively collected from January 2006 to December 2009. The general data of enrolled patients, including age, gender, body weight, BMI, and waist circumference were recorded. All patients underwent an open-access transoral upper gastrointestinal endoscopy, which was performed by experienced endoscopists, and the findings of each case were collected. The exclusion criteria included prior gastric surgery, and the presence of esophageal varices or peptic ulcers.

The individuals with BE were identified, and BE was defined as endoscopically suspected esophageal metaplasia with specialized intestinal metaplasia documented by biopsy pathology. They were then age- and sex-matched at a ratio of 1:2 with cases with EE, and with cases with normal esophagocardial junction who served as the control group. The presence of hiatal

Correspondence to: Shou-Wu Lee

Division of Gastroenterology, Department of Internal Medicine, Taichung Veterans General Hospital, Taichung 1650 Taiwan Boulevard, Sec. 4, Taichung 40705, Taiwan

Tel: +886-4-23592525 (ext. 3306), Fax: +886-4-23595046, E-mail: ericest@vghtc.gov.tw

Received on April 19, 2016. Revised on May 30, 2016. Accepted on July 7, 2016. Published online December 16,2016 pISSN 1976-2283 eISSN 2005-1212 https://doi.org/10.5009/gnl16211

@ This is an Open Access article distributed under the terms of the Creative Commons Attribution Non-Commercial License (http://creativecommons.org/licenses/by-nc/4.0) which permits unrestricted non-commercial use, distribution, and reproduction in any medium, provided the original work is properly cited. 
hernia of each case was also collected. These enrolled patients were stratified into two groups according to BMI: normal weight group (BMI $<25 \mathrm{~kg} / \mathrm{m}^{2}$ ) and overweight/obesity group (BMI $\geq 25$ $\mathrm{mg} / \mathrm{m}^{2}$ ); or stratified into two groups according to waist circumference: normal waist group (waist circumference $<90 \mathrm{~cm}$ for men and $<80 \mathrm{~cm}$ for women) and abdominal obesity group (waist circumference $\geq 90 \mathrm{~cm}$ for men and $\geq 80 \mathrm{~cm}$ for women).

Data including age, body weight, BMI, and waist circumference are expressed as standard deviation of mean for each of the measured parameters. Gender and the positive ratio of each stratified group are expressed as a percentage of the total patient number. Statistical comparisons were made using Pearson chi-square test to compare the effects of gender and the positive ratio of each stratified group. Independent t-test was used to analyze age, body weight, BMI, and waist circumference. A p-value below 0.05 was considered statistically significant. Multivariate Cox regression was used to examine the strength of as- sociation between obesity and $\mathrm{EE}$, or $\mathrm{BE}$, as shown by the odds ratios (OR) with 95\% confidence interval (CI).

\section{RESULTS}

Among all 4,113 enrolled subjects in our study, 2,601 (63.2\%), $1,462(35.5 \%)$, and 50 (1.3\%) cases owing normal esophagocardial junction, EE, and BE respectively. They were then ageand sex-matched at a ratio of 1:2 with $100 \mathrm{EE}$ cases, and 100 normal cases. The patients' characteristics are displayed in Table 1. The mean ages and gender ratios of these three groups were similar. The EE and BE individuals owned higher ratio of hiatal hernia (28\% and 38\%, respectively) than the normal ones did (9\%). To the BE subjects, 48 (96\%) and two (4\%) cases were belonged to short- and long-segment, respectively.

The individuals in the EE group $\left(71.10 \mathrm{~kg}, 26.68 \mathrm{~kg} / \mathrm{m}^{2}, 87.24\right.$ $\mathrm{cm}$ ) had significantly ( $\mathrm{p}=0.001)$ higher body weight, BWI, and

Table 1. Characteristics of the Enrolled Individuals

\begin{tabular}{|c|c|c|c|c|c|c|c|}
\hline \multirow{2}{*}{ Variable } & \multicolumn{2}{|c|}{ Normal $(n=100)$} & \multicolumn{2}{|c|}{$\mathrm{EE}(\mathrm{n}=100)$} & \multicolumn{2}{|c|}{$\mathrm{BE}(\mathrm{n}=50)$} & \multirow{2}{*}{ p-value } \\
\hline & $\operatorname{mean}_{ \pm} \mathrm{SD}$ & No. $(\%)$ & mean $\pm S D$ & No. (\%) & mean \pm SD & No. $(\%)$ & \\
\hline Age, yr & $54.16 \pm 12.98$ & & $54.43 \pm 13.11$ & & $54.32 \pm 13.06$ & & $1.000^{*}$ \\
\hline Sex & & & & & & & $1.000^{\dagger}$ \\
\hline Male & & $56(56)$ & & $56(56)$ & & $28(56)$ & \\
\hline Female & & $44(44)$ & & $44(44)$ & & $22(44)$ & \\
\hline Hiatal hernia & & $9(9)$ & & $28(28)$ & & $19(38)$ & $0.001^{*, \mp}$ \\
\hline $\mathrm{BW}, \mathrm{kg}$ & $63.97 \pm 8.96$ & & $71.10 \pm 12.63$ & & $65.36 \pm 12.29$ & & $0.001^{*, \S}$ \\
\hline BMI, $\mathrm{kg} / \mathrm{m}^{2}$ & $23.64 \pm 1.12$ & & $26.68 \pm 3.06$ & & $24.28 \pm 2.88$ & & $0.001^{*, \S}$ \\
\hline Waist, cm & $80.73 \pm 7.43$ & & $87.25 \pm 10.01$ & & $78.88 \pm 9.41$ & & $0.001^{*, \S}$ \\
\hline
\end{tabular}

EE, erosive esophagitis; BE, Barrett's esophagus; BW, body weight; BMI, body mass index.

${ }^{*}$ Independent t-test; ${ }^{\dagger}$ Pearson chi-square test; ${ }^{\ddagger}$ Comparison between EE and normal groups or BE and normal groups; ${ }^{\circledR}$ Comparison between EE and normal groups.
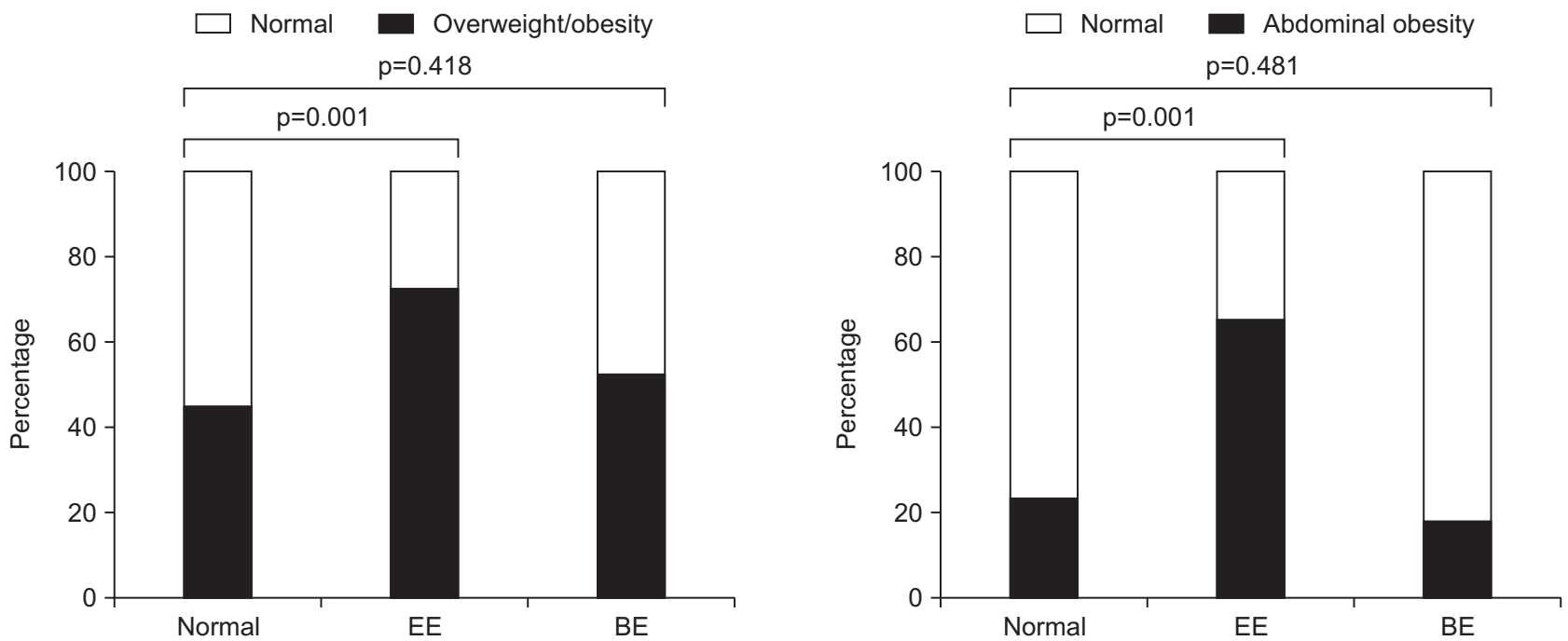

Fig. 1. Proportion of obesity in each group. EE, erosive esophagitis; BE, Barrett's esophagus. 
waist circumference than those in the normal group $(63.97 \mathrm{~kg}$, $23.64 \mathrm{~kg} / \mathrm{m}^{2}, 80.73 \mathrm{~cm}$ ) and BE group (65.36 kg, $24.28 \mathrm{~kg} / \mathrm{m}^{2}$, $78.88 \mathrm{~cm})$. As disclosed in Fig. 1, 45 (45\%), 72 (72\%), and 26 $(52 \%)$ of patients were overweight/obese in the normal, EE, and $\mathrm{BE}$ groups, respectively. The difference was significant $(\mathrm{p}=0.001)$ between the normal group and EE group. Similarly, among the individuals in the EE group, a large proportion of patients had abdominal obesity (65\%) compared with those in the normal group (23\%). The individuals in the BE group had a relatively lower percentage (18\%) of patients with abdominal obesity.

The strength of the association between each group and obesity is shown in Table 2, and the positive association with EE was significant in patients with overweight/obesity (OR, 3.14; 95\% CI, 1.75 to 5.66), and in those with abdominal obesity (OR, 6.22 ; 95\% CI, 3.34 to 11.57). The association was nonsignificant between BE and overweight/obesity (OR, 1.32; 95\% CI, 0.67 to 2.61), and between BE and abdominal obesity (OR, 0.73; 95\% CI, 0.31 to 1.73$)$.

Table 2. ORs and 95\% CIs of Associated Obesity with Erosive Esophagitis and Barrett's Esophagus Analyzed with Multivariate Cox Regression

\begin{tabular}{lll}
\hline \multicolumn{1}{c}{ Endoscopic finding } & OR & $95 \% \mathrm{CI}$ \\
\hline Erosive esophagitis & & \\
Normal & 1.00 & Reference \\
Obesity/overweight & 3.14 & $1.75-5.66$ \\
Central obesity & 6.22 & $3.34-11.57$ \\
Barrett’s esophagus & & \\
Normal & 1.00 & Reference \\
Obesity/overweight & 1.32 & $0.67-2.61$ \\
Central obesity & 0.73 & $0.31-1.73$ \\
\hline
\end{tabular}

OR, odds ratio; CI, confidence interval.

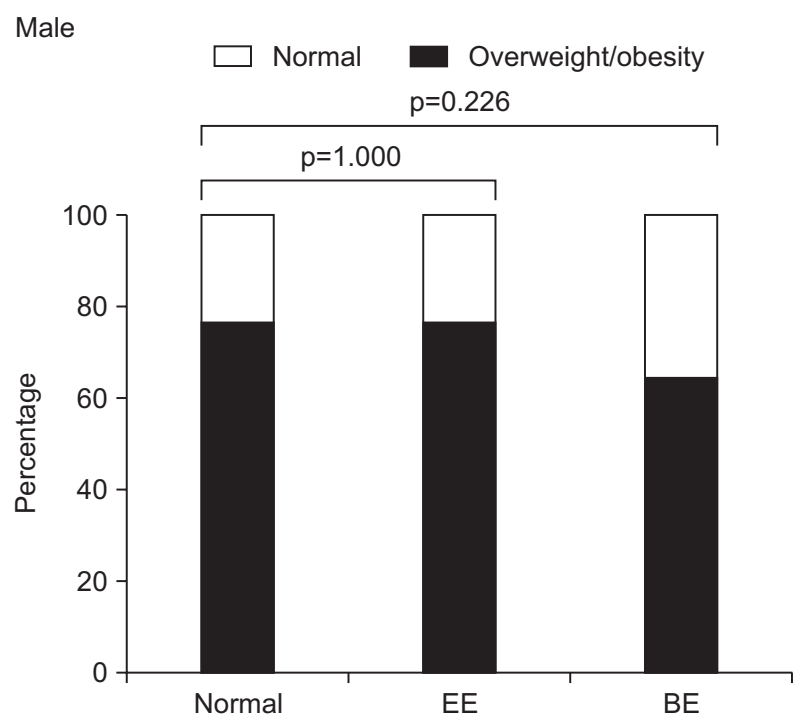

Fig. 2. Proportion of obesity in male subjects in each group. $\mathrm{EE}$, erosive esophagitis; BE, Barrett's esophagus.
The associations of obesity and the strengths of those associations in male subjects in each group are shown in Table 3 and Fig. 2, respectively. There were 43 (76.8\%), 43 (76.8\%), and 18 (64.3\%) patients with overweight/obesity in the subgroups of men with normal, EE, and BE, respectively. The differences were nonsignificant between each subgroup. The male individuals with EE (73.2\%) exhibited the highest prevalence rate of abdominal obesity compared with those with normal (14.3\%) or BE (25\%). The positive association with EE was significant in the cases with abdominal obesity (OR, 16.40; 95\% CI, 6.31 to 42.56). In contrast, the association between overweight/obesity and EE was not significant (OR, 2.12; 95\% CI, 0.77 to 5.79). Neither overweight/obesity nor abdominal obesity had a positve association with BE in the male population.

The associations of obesity and the strengths of those associations in female patients in each subgroup are disclosed in Table 4 and Fig. 3, respectively. There were two (4.5\%), 23 (52.3\%), and eight (36.4\%) female patients with overweight/

Table 3. ORs and 95\% CIs of Associated Obesity with Male Erosive Esophagitis and Barrett's Esophagus Analyzed with Multivariate Cox Regression

\begin{tabular}{lrl}
\hline \multicolumn{1}{c}{ Endoscopic finding } & OR & $95 \% \mathrm{CI}$ \\
\hline Erosive esophagitis & & \\
$\quad$ Normal & 1.00 & Reference \\
Obesity/overweight & 2.12 & $0.77-5.79$ \\
Central obesity & 16.40 & $6.31-42.56$ \\
Barrett's esophagus & & \\
Normal & 1.00 & Reference \\
Obesity/overweight & 0.54 & $0.20-1.47$ \\
Central obesity & 2.00 & $0.64-6.23$ \\
\hline
\end{tabular}

$\mathrm{OR}$, odds ratio; $\mathrm{CI}$, confidence interval.

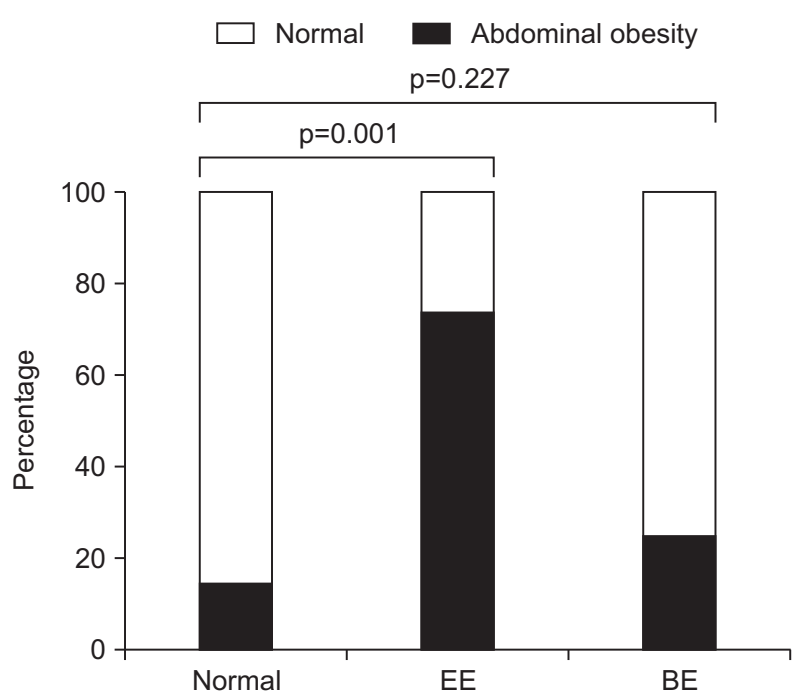


obesity in the subgroups of women with normal, EE, and BE, respectively. There was a significantly $(p=0.001)$ higher prevalence of overweight/obesity in the EE and BE groups compared with the normal group. The female individuals with EE (54.5\%) had a higher prevalence rate of abdominal obesity than that of patients in the normal (34.1\%) or BE (9.1\%) groups, but the differences were nonsignificant. The positive associations were significant between overweight/obesity and EE (OR, 22.98; 95\% CI, 4.95 to 106.94), and BE (OR, 11.99; 95\% CI, 2.27 to 63.32). In contrast, no associations existed between abdominal obesity and $\mathrm{BE}$ or $\mathrm{EE}$.

\section{DISCUSSION}

In our study, patients with EE had a significantly higher body weight, BMI, waist circumference, and a higher prevalence of overweight/obesity and abdominal obesity, compared with

Table 4. ORs and 95\% CIs of Associated Obesity with Female Erosive Esophagitis and Barrett's Esophagus Analyzed with Multivariate Cox Regression

\begin{tabular}{lrl}
\hline \multicolumn{1}{c}{ Endoscopic finding } & OR & 95\% CI \\
\hline Erosive esophagitis & & \\
Normal & 1.00 & Reference \\
Obesity/overweight & 22.98 & $4.95-106.94$ \\
Central obesity & 2.00 & $0.64-6.23$ \\
Barrett’s esophagus & & \\
Normal & 1.00 & Reference \\
Obesity/overweight & 11.99 & $2.27-63.32$ \\
Central obesity & 0.20 & $0.40-1.00$ \\
\hline
\end{tabular}

OR, odds ratio; CI, confidence interval.

Female

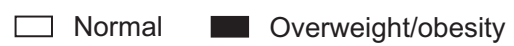
$\mathrm{p}=0.001$

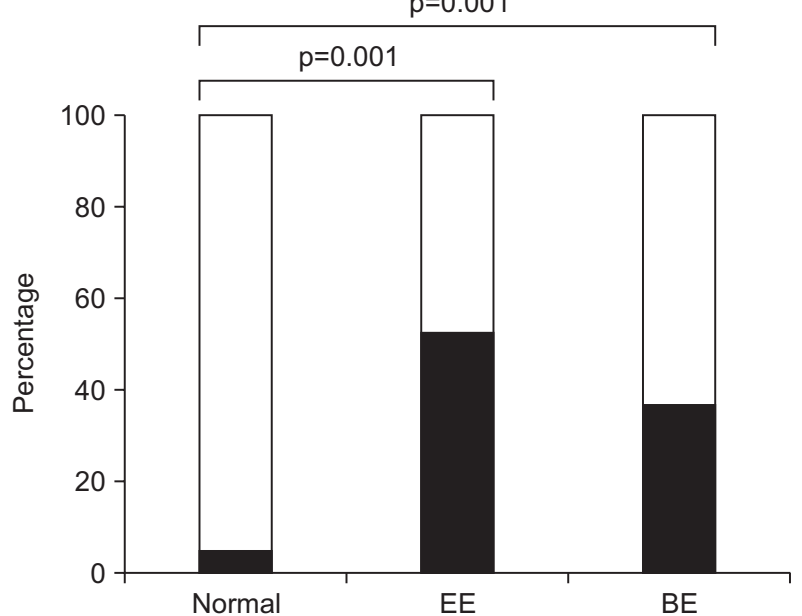

those without. Furthermore, there was a significant positive association of EE with abdominal obesity in men. In contrast, women with EE had a significantly higher prevalence rate of overweight/obesity than women without EE. Thus, obesity was considered to be a contributing factor in EE, but the roles of body weight parameters showed gender differences in the pathogenesis of GERD.

A large meta-analysis and systematic review of epidemiological studies conducted in North America and Western European countries reported that the OR for increased GERD symptoms and esophagitis was 1.43 (95\% CI, 1.19 to 1.77) for individuals with BMI from 25 to 30 and 1.94 (95\% CI, 1.47 to 2.57) for those with BMI over 30, as compared to individuals with normal BMI. $^{4}$ Both high waist circumference and BMI were associated with a significant increase in reflux episodes based on the 24hour pH-metry report. ${ }^{6}$

With respect to the impact of gender on GERD, one large population-based cohort study found that obese women had an increased risk for GERD symptoms compared with obese men, ${ }^{7}$ although a previous systemic review found no association between gender and obesity cases with GERD. ${ }^{8}$ Another cohort study enrolled more than 10,000 women and found that BMI, rather than waist-to-hip ratio (WHR), was associated with GERD symptoms. ${ }^{9}$ In individuals with EE, a meta-analysis of 7,078 cases revealed a positive association (OR, 1.76; 95\% CI, 1.16 to 2.68) between obesity and increased risk of EE. ${ }^{3}$

The hypothesis that higher waist circumference contributes to GERD might involve a mechanical pathogenesis related to the extrinsic gastric compression caused by the abdominal adipose tissue, which would tend to increase intragastric pressure, thereby inducing relaxation of the lower esophageal sphincter leading to abnormal acid reflux..$^{10}$ The aforementinoned mechanism

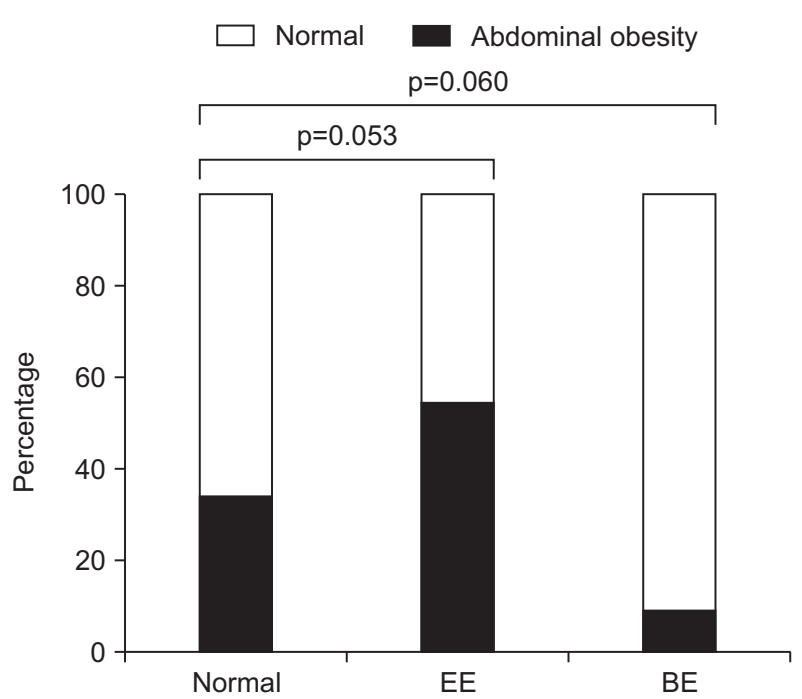

Fig. 3. Proportion of obesity in female subjects in each group. $\mathrm{EE}$, erosive esophagitis; $\mathrm{BE}$, Barrett's esophagus. 
may explain why higher waist circumference (i.e., abdominal obesity) is a known key factor in both the symptoms and perhaps even the complications of GERD. The findings of this study are compatible with the conclusion of our previous study, ${ }^{11}$ which showed that obese men had more severe endoscopic and clinical presentations compared with those of obese women.

Our results failed to find a positive association between $\mathrm{BE}$ and obesity, including high BMI and high waist circumference. Most previous data suggest that the association between BMI and $\mathrm{BE}$ is not significant. ${ }^{12-16}$ In contrast, abdominal obesity, measured by waist circumference or WHR, is considered to be a risk factor for BE. ${ }^{14-16}$ In one US case-control study, individuals with a high WHR had an increased risk of developing BE (OR, 2.4; 95\% CI, 1.4 to 3.9 ).

The differences between preious reports and our data may be explained at least in part by the different prevalence rates of $\mathrm{BE}$ types in the East. In Asian countries, most BE cases are of the short-segment type. ${ }^{17-19}$ One study found abdominal obesity was associated with long-segment BE, but not with short-segment BE. ${ }^{16}$ There were only two cases (4\%) with long-segment BE in our enrolled individuals, and thus obesity was only associated with a limited increased risk of BE. Furthermore, according to a recent study, ordinary risk factors for $\mathrm{BE}$, such as male and hiatal hernia, cannot be applied for shorter-segment BE with a length $<1 \mathrm{~cm}^{20}$

With regard to the women with $\mathrm{BE}$ in our study, there was a positive association with overweight/obesity, but not with abdominal obesity. The results were similar to those of a previous U.S. study, which enrolled 15,861 women. ${ }^{21}$ Two recent studies conducted in the United State and Australia, respectively, yielded conflicting results for female patients. ${ }^{22,23}$ Besdies, our study found no association of BMI, or waist circumference, with BE in men. This discrepancy might be explained by differences in the obesity patterns, especially with respect to the pattern of visceral adipose tissue deposition, in the different gender. Obese men might tend to have more centralized, metabolically active visceral fat, while women might deposit more body fat in their subcutaneous tissues. The association between obesity and BE in different gender should need further investigation.

There were some limitations in our study. First, characteristics such as cigarette smoking, alcohol consumption and Helicobacteri pylori infection in our study, which are considered to be either risk or protective factors in $\mathrm{EE}$ and $\mathrm{BE}$, were not analyzed. Second, there were no data on GERD symptoms in the study's enrolled patients which may have potentially resulted in misclassification bias. Thirdly, the standard of obeisty might differ to ethnic groups of populations in the East and West. Lastly, our study design was hospital-based and included only a small number of cases. The present results could not be generalized to the general Chinese population. Further research using representative samples of the general population are needed to confirm these results.
In conclusion, in the present study, obesity was demonstrated to be a contributing factor in EE, but men (high waist circumference) and women (high BMI) exhibited a different obesity pattern with respect to the pathogenesis of GERD. The association of BE and obesity was not significant, except in female BE patients, who had a relatively high prevalence of overweight/ obesity.

\section{CONFLICTS OF INTEREST}

No potential conflict of interest relevant to this article was reported.

\section{REFERENCES}

1. Vakil N, van Zanten SV, Kahrilas P, Dent J, Jones R; Global Consensus Group. The Montreal definition and classification of gastroesophageal reflux disease: a global evidence-based consensus. Am J Gastroenterol 2006;101:1900-1920.

2. Sharma P. Clinical practice: Barrett's esophagus. N Engl J Med 2009;361:2548-2556.

3. El-Serag $\mathrm{H}$. The association between obesity and GERD: a review of the epidemiological evidence. Dig Dis Sci 2008;53:2307-2312.

4. Hampel H, Abraham NS, El-Serag HB. Meta-analysis: obesity and the risk for gastroesophageal reflux disease and its complications. Ann Intern Med 2005;143:199-211.

5. Watari J, Hori K, Toyoshima F, et al. Association between obesity and Barrett's esophagus in a Japanese population: a hospitalbased, cross-sectional study. BMC Gastroenterol 2013;13:143.

6. El-Serag HB, Ergun GA, Pandolfino J, Fitzgerald S, Tran T, Kramer JR. Obesity increases oesophageal acid exposure. Gut 2007;56:749-755.

7. Nilsson M, Johnsen R, Ye W, Hveem K, Lagergren J. Obesity and estrogen as risk factors for gastroesophageal reflux symptoms. JAMA 2003;290:66-72.

8. Dent J, El-Serag HB, Wallander MA, Johansson S. Epidemiology of gastro-oesophageal reflux disease: a systematic review. Gut 2005;54:710-717.

9. Jacobson BC, Somers SC, Fuchs CS, Kelly CP, Camargo CA Jr. Body-mass index and symptoms of gastroesophageal reflux in women. N Engl J Med 2006;354:2340-2348.

10. El-Serag H. Role of obesity in GORD-related disorders. Gut 2008;57:281-284.

11. Lee SW, Lien HC, Chang CS, Peng YC, Ko CW, Chou MC. Impact of body mass index and gender on quality of life in patients with gastroesophageal reflux disease. World J Gastroenterol 2012;18:5090-5095.

12. Smith KJ, O'Brien SM, Smithers BM, et al. Interactions among smoking, obesity, and symptoms of acid reflux in Barrett's esophagus. Cancer Epidemiol Biomarkers Prev 2005;14(11 Pt 1):24812486.

13. Gerson LB, Ullah N, Fass R, Green C, Shetler K, Singh G. Does 
body mass index differ between patients with Barrett's oesophagus and patients with chronic gastro-oesophageal reflux disease? Aliment Pharmacol Ther 2007;25:1079-1086.

14. Corley DA, Kubo A, Levin TR, et al. Abdominal obesity and body mass index as risk factors for Barrett's esophagus. Gastroenterology 2007;133:34-41.

15. Edelstein ZR, Farrow DC, Bronner MP, Rosen SN, Vaughan TL. Central adiposity and risk of Barrett's esophagus. Gastroenterology 2007;133:403-411.

16. Kramer JR, Fischbach LA, Richardson P, et al. Waist-to-hip ratio, but not body mass index, is associated with an increased risk of Barrett's esophagus in white men. Clin Gastroenterol Hepatol 2013;11:373-381.e1.

17. Kim JH, Rhee PL, Lee JH, et al. Prevalence and risk factors of Barrett's esophagus in Korea. J Gastroenterol Hepatol 2007;22:908912.

18. Okita K, Amano Y, Takahashi Y, et al. Barrett's esophagus in Japanese patients: its prevalence, form, and elongation. J Gastroenterol
2008;43:928-934.

19. Zhang M, Fan XS, Zou XP. The prevalence of Barrett's esophagus remains low in Eastern China: single-center 7-year descriptive study. Saudi Med J 2012;33:1324-1329.

20. Balasubramanian G, Singh M, Gupta N, et al. Prevalence and predictors of columnar lined esophagus in gastroesophageal reflux disease (GERD) patients undergoing upper endoscopy. Am J Gastroenterol 2012;107:1655-1661.

21. Jacobson BC, Chan AT, Giovannucci EL, Fuchs CS. Body mass index and Barrett's oesophagus in women. Gut 2009;58:1460-1466.

22. Kubo A, Cook MB, Shaheen NJ, et al. Sex-specific associations between body mass index, waist circumference and the risk of Barrett's oesophagus: a pooled analysis from the international BEACON consortium. Gut 2013;62:1684-1691.

23. Kendall BJ, Macdonald GA, Hayward NK, et al. The risk of Barrett's esophagus associated with abdominal obesity in males and females. Int J Cancer 2013;132:2192-2199. 